\title{
Dystonia and tremor induced by peripheral trauma: predisposing factors
}

\author{
JOSEPH JANKOVIC, CHRIS VAN DER LINDEN \\ From the Department of Neurology, Baylor College of Medicine, Houston, Texas, USA
}

SUMMARY Movement disorders are usually of central origin, but sometimes involuntary movements occur after peripheral trauma. Twenty eight patients, 13 women and 15 men, mean age 37 years (range 15-78), were studied with dystonia or tremor in whom the onset of abnormal movements was related, in time and in distribution, to injury of a body part. Among 23 patients with latency of less than one year after injury, focal dystonia of the involved body part was found in 18, nine of whom had associated reflex sympathetic dystrophy (RSD). One of five patients with peripherally induced tremor had RSD. Abnormal electromyography or nerve conduction velocities were found in the affected limb in four patients, but other electrophysiologic techniques provided evidence for disturbed central function. In 15 patients $(65 \%)$ possible predisposing factors may have contributed to the pathogenesis of the trauma induced abnormal involuntary movements.

Movement disorders are usually attributed to a dysfunction in the extrapyramidal system, but sometimes involuntary movements occur after an acute peripheral injury. Such peripherally induced movement disorders are rare when compared with the relatively high incidence of local limb trauma..$^{1-5}$ One possible explanation for the relatively low frequency of movement disorders associated with peripheral injuries is that the causal relationship between injury and subsequent movement disorder is not recognised, it is dismissed as insignificant, or it is considered psychogenic. Another reason for the uncommon occurrence of peripherally induced movement disorders could be the possibility that special vulnerability or predisposition to motor disturbances is necessary before the involuntary movements become expressed. We therefore studied patients with traumainduced movement disorders with regard to possible predisposing factors.

\section{Patients and methods}

All patients in whom a causal relationship between a previous injury and dystonia or tremor was strongly suspected were selected from a database of 3500 patients with various movement disorders evaluated at the Movement Disorder

Address for reprit ts requests: Dr Jankovic, Department of Neurology, Baylor College of Medicine, Houston, Texas 77030, USA.

Received 11 March 1988 and in revised form 31 May 1988. Accepted 13 June 1988
Clinic, Baylor College of Medicine, Department of Neurology. Only patients with an obvious topographical and temporal relationship between the peripheral trauma and subsequent local movement disorder were included. In an attempt to exclude patients with remote or unrelated trauma, latency not longer than 1 year between trauma and the onset of a movement disorder was allowed (table 1). We excluded five patients with rather convincing causal relationship between peripheral injury and subsequent movement disorder because there was a delay of more than 1 year after injury before onset of the movement disorder (table 2). Patients with hemifacial spasm, ${ }^{6}$ segmental myoclonus, ${ }^{7}$ edentulous orodyskinesias, ${ }^{8}$ and amputation stump dyskinesias ${ }^{9}$ were excluded because peripheral origin for these movement disorders is relatively well established. We have also excluded patients with head injury because direct damage to central nervous system (CNS) structures could not be ruled out. ${ }^{10} 11$ Likewise, patients with spine injury with evidence of spinal cord damage were excluded. Although "psychiatric disease" may have contributed to the expression of the movement disorders in some of our patients we made an effort to exclude patients with purely psychogenic movement disorders.

In addition to a detailed neurological examination, all patients were videotaped. Neurophysiologic studies including nerve conduction velocities (NCV) and electromyography (EMG) were performed in 18 patients, and somatosensory evoked potentials (SEPs) to stimulation of median and tibial nerves were measured in six patients. In five patients polyelectromyographic (PEMG) recordings with surface electrodes of involved muscle groups were made and included recordings at rest, during attempted volitional movements of the affected body part, reinforcement manoeuvres and during phasic and tonic stretch (vibration) of involved muscles. 
Table 1 Patients with peripheral trauma-induced dystonia

\begin{tabular}{|c|c|c|c|c|c|c|c|}
\hline Patient & $\begin{array}{l}\text { Sex/age } \\
\text { (years) }\end{array}$ & $\begin{array}{l}\text { Type of } \\
\text { injury }\end{array}$ & $\begin{array}{l}\text { Movement } \\
\text { disorder } \\
\text { at onset }\end{array}$ & $\begin{array}{l}\text { Movement } \\
\text { disorder } \\
\text { at present }\end{array}$ & $\begin{array}{l}\text { Latency } \\
\text { between injury } \\
\text { and movement } \\
\text { disorder }\end{array}$ & $\begin{array}{l}\text { Possible } \\
\text { predisp. factors } \\
\text { for movement } \\
\text { disorder }\end{array}$ & $\begin{array}{l}\text { Neurophys } \\
\text { studies }\end{array}$ \\
\hline $1^{*}$ & $F / 33$ & $\begin{array}{l}\mathrm{R} \text { elbow injury, } \\
\text { casted }\end{array}$ & $\mathrm{R}$ hand dystonia & $\begin{array}{c}\text { Generalised } \\
\text { dystonia }\end{array}$ & $\begin{array}{l}10 \text { months after } \\
\text { injury, but } \\
\text { immediately after } \\
\text { cast removal }\end{array}$ & $\begin{array}{l}\text { Neuroleptics/Ashken- } \\
\text { azi-Jewish origin }\end{array}$ & $\begin{array}{c}\text { EMG:N NCV:N } \\
\text { PEMG:Abn }\end{array}$ \\
\hline $\begin{array}{l}2^{*} \\
3^{*}\end{array}$ & $\begin{array}{l}\mathbf{M} / 30 \\
\mathbf{F} / 33\end{array}$ & $\begin{array}{l}\text { Cut } R \text { thumb, casted } \\
\text { Heavy can dropped } \\
\text { on } R \text { foot, casted }\end{array}$ & $\begin{array}{l}\mathbf{R} \text { forearm dystonia } \\
\mathbf{R} \text { foot dystonia }\end{array}$ & $\begin{array}{l}\text { Same } \\
\text { Same }\end{array}$ & $\begin{array}{l}2 \text { weeks } \\
2 \text { months }\end{array}$ & $\begin{array}{l}\text { None } \\
\text { Neuroleptics }\end{array}$ & $\begin{array}{l}\text { SEPs:N } \\
\text { EMG:N NCV:N } \\
\text { SEP:N }\end{array}$ \\
\hline $4^{*}$ & $F / 34$ & L foot sprain, casted & L foot dystonia & L BKA & 4 weeks & 8 weeks premature & $\begin{array}{l}\text { EMG:Abn } \\
\text { NCV:Abn } \\
\text { SEP:N } \\
\text { PEMG:Abn }\end{array}$ \\
\hline 5 & $F / 48$ & Laminectomy & L foot dystonia & $\begin{array}{l}\text { Paroxysmal } \\
\text { kinesigenic } \mathbf{L} \\
\text { hemidystonia }\end{array}$ & 2 months & $\begin{array}{l}\text { Family history of } \\
\text { paroxysmal } \\
\text { dystonia }\end{array}$ & EMG:N NCV:N \\
\hline 6 & $\mathbf{M} / 22$ & Facial injury & $\begin{array}{l}\text { Oromandibular } \\
\text { dystonia }\end{array}$ & $\begin{array}{l}\text { Cranial-cervical } \\
\text { dystonia }\end{array}$ & 12 months & Developmental delay & NA \\
\hline 7 & $F / 17$ & $\begin{array}{l}\text { L ankle sprain and } L \\
\text { hip surgery, } \\
\text { casted }\end{array}$ & L foot dystonia & $\begin{array}{l}\text { Generalised } \\
\text { dystonia }\end{array}$ & 1 month & $\begin{array}{l}\text { Family history of ET } \\
\text { and dystonia }\end{array}$ & PEMG:Abn \\
\hline $8^{*}$ & $\mathrm{M} / 18$ & $\begin{array}{l}\text { R metacarpal } \\
\text { phalangeal Fx, } \\
\text { casted }\end{array}$ & Occupational cramp & $\begin{array}{l}\text { ET and } \\
\text { occupational } \\
\text { cramp }\end{array}$ & 2 months & $\begin{array}{l}\text { Hyperactive as a child } \\
\text { treated with } \\
\text { stimulants }\end{array}$ & NA \\
\hline 9 & $\mathrm{M} / 52$ & Back injury & L foot dystonia & $\begin{array}{l}\text { Painful leg-moving } \\
\text { toes syndrome }\end{array}$ & 1 month & None & PEMG:Abn \\
\hline 10 & $\mathbf{M} / 52$ & Laminectomy & Cervical dystonia & Same & 1 day & $\begin{array}{l}\text { ET since early } \\
\text { adulthood }\end{array}$ & PEMG:Abn \\
\hline 11 & $\mathbf{F} / 29$ & Neck injury & Cervical dystonia & $\begin{array}{l}\text { Same and bilateral } \\
\text { hand tremor }\end{array}$ & 1 day & None & EMG:N NCV:N \\
\hline 12 & $\mathbf{M} / 23$ & $\begin{array}{l}\mathbf{R} \text { hand injury with } \\
\text { amputation of } \\
\text { 3rd digit }\end{array}$ & $\begin{array}{l}\text { Involuntary finger } \\
\text { movements }\end{array}$ & $\begin{array}{l}\text { Painful hand } \\
\text { moving finger } \\
\text { syndrome }\end{array}$ & 2 weeks & $\begin{array}{l}\text { Dystonic reaction to } \\
\text { haloperidol }\end{array}$ & $\begin{array}{l}\text { EMG:N NCV:N } \\
\text { SEP:N }\end{array}$ \\
\hline 13 & $F / 39$ & L 5th digit Fx & $\mathrm{L}$ hand dystonia & $\begin{array}{l}\text { Paroxysmal L } \\
\text { hemidystonia }\end{array}$ & 6 months & $\begin{array}{l}\text { Family history of } \\
\text { paroxysmal } \\
\text { dystonia }\end{array}$ & EMG:N \\
\hline $\begin{array}{l}14^{*} \\
15^{*}\end{array}$ & $\begin{array}{l}\mathbf{M} / 54 \\
\mathbf{M} / 33\end{array}$ & $\begin{array}{l}\text { Pelvic Fx } \\
\mathbf{R} \text { ulnar nerve } \\
\text { compression, } \\
\text { casted }\end{array}$ & $\begin{array}{l}\text { L leg dystonia } \\
\text { Hand "cramp" }\end{array}$ & $\begin{array}{l}\text { Same } \\
\text { Hand dystonia }\end{array}$ & $\begin{array}{l}3 \text { weeks } \\
7 \text { weeks }\end{array}$ & $\begin{array}{l}\text { None } \\
\text { None }\end{array}$ & $\begin{array}{l}\text { EMG:Abn } \\
\text { EMG:N }\end{array}$ \\
\hline, 16 & $\mathrm{M} / 28$ & $R$ leg injury & $\mathrm{R}$ foot tremor and & Foot dystonia & 2 days & None & EMG:N \\
\hline $17^{*}$ & $F / 78$ & $\begin{array}{l}\mathbf{R} \text { hand-finger Fxs } \\
\text { casted }\end{array}$ & $\begin{array}{l}\text { R 4th and 5th finger } \\
\text { flexion thumb } \\
\text { extension }\end{array}$ & Hand dystonia & 1 week & Familial ET & EMG:N \\
\hline $18^{*}$ & $F / 15$ & L foot sprain & $L$ foot dystonia & $\begin{array}{l}\text { L leg dystonia, } R \\
\text { foot tremor }\end{array}$ & 1 week & Family history of ET & EMG:N SEP:N \\
\hline 19 & $\mathbf{M} / 38$ & $\begin{array}{l}\text { Laminectomy, } \\
\text { complicated }\end{array}$ & Tremor in both legs & Parkinsonism & 9 months & ARC & SEPs:N \\
\hline $20^{*}$ & $F / 49$ & $\begin{array}{l}\text { Vibration trauma to } \\
R \text { arm }\end{array}$ & $\mathbf{R}$ arm tremor & Same & 4 months & None & EMG:N NCV:N \\
\hline 21 & $\mathrm{M} / 56$ & Neck injury & $\mathbf{R}$ hand tremor & $\begin{array}{l}\text { Cervical dystonia } \\
\text { and } R \text { hand } \\
\text { resting tremor }\end{array}$ & 1 day & $\begin{array}{l}\text { Long term use of } \\
\text { antidepressants }\end{array}$ & $\begin{array}{l}\text { EMG:N } \\
\text { NCV:Abn }\end{array}$ \\
\hline 22 & $\mathrm{M} / 44$ & \multirow{2}{*}{$\begin{array}{l}\text { Electric shock to } \\
\mathbf{R} \text { hand } \\
\mathbf{R} \text { wrist laceration }\end{array}$} & \multirow{2}{*}{$\begin{array}{l}\text { Bilateral hand } \\
\text { intention tremor } \\
\mathbf{R} \text { hand tremor }\end{array}$} & \multirow{2}{*}{$\begin{array}{l}\text { Segmental } \\
\text { myoclonus } \\
R \text { hand tremor } \\
(6 \mathrm{~Hz})\end{array}$} & 1 day & None & NA \\
\hline 23 & $\mathbf{M} / 25$ & & & & 3 weeks & Drug abuse & $\begin{array}{l}\text { EMG: ulnar } \\
\text { Neuropathy }\end{array}$ \\
\hline
\end{tabular}

Key: $\mathrm{A}=$ absent, $\mathrm{Abn}=$ abnormal, $\mathrm{ARC}=$ Aids related complex, $\mathrm{BKA}=$ below the knee amputation, $\mathrm{EMG}=$ electromyography, $\mathrm{ET}=$ essential tremor, $\mathrm{L}=$ Left, $\mathrm{N}=$ Normal, NA $=$ not available or not done, NCV = nerve conduction velocities, PEMG $=$ polyelectromyography, $\mathrm{R}=\mathrm{Right}, \mathrm{RSD}=\mathrm{reflex}$ - sympathetic dystrophy, SEPs = somatosensory evoked potentials.

*Patient with concomitant RSD.

\section{Results}

Twenty three patients, 10 women and 13 men, mean age 37 years (range: 15 to 78 ) in whom association between focal dystonia or tremor and previous local injury of the same body part was very likely, were identified (table 1). In this group of patients the movement disorder was first noted 1 day to 1 year after the injury. Eighteen patients had a focal limb dystonia, nine of whom had associated reflex sympathetic dystrophy (RSD), characterised by pain, hyperaesthesia, vasomotor disturbances and trophic changes in 
Table 2 Patients with peripheral trauma-induced dystonia with latency more than one year

\begin{tabular}{|c|c|c|c|c|c|c|c|}
\hline Patient & $\begin{array}{l}\text { Sex/age } \\
\text { (years) }\end{array}$ & $\begin{array}{l}\text { Type of } \\
\text { injury }\end{array}$ & $\begin{array}{l}\text { Movement } \\
\text { disorder } \\
\text { at onset }\end{array}$ & $\begin{array}{l}\text { Movement } \\
\text { disorder } \\
\text { at present }\end{array}$ & $\begin{array}{l}\text { Latency } \\
\text { between injury } \\
\text { and movement } \\
\text { disorder }\end{array}$ & $\begin{array}{l}\text { Possible } \\
\text { predisp. factors } \\
\text { for movement } \\
\text { disorder }\end{array}$ & $\begin{array}{l}\text { Neurophys } \\
\text { studies }\end{array}$ \\
\hline$\overline{24}$ & $F / 41$ & $\begin{array}{l}\text { GSW to R brachial } \\
\text { plexus }\end{array}$ & $\begin{array}{l}\mathrm{R} \text { action focal hand } \\
\text { dystonia }\end{array}$ & Same & 5 years & Head injury & EMG:Abn \\
\hline 25 & $\mathrm{M} / 44$ & $L$ foot fracture & $L$ foot dystonia & $\begin{array}{l}\text { ET, writer's cramp } \\
\text { and } L \text { foot } \\
\text { dystonia }\end{array}$ & 6 years & Family history of ET & NA \\
\hline 26 & $F / 37$ & $\mathbf{L}$ ankle sprain & $\begin{array}{l}\text { L foot action } \\
\text { dystonia }\end{array}$ & Same & 6 years & $\begin{array}{l}\text { Meningoenchephalitis, } \\
\text { neuroleptics, family } \\
\text { history of } \\
\text { Parkinsonism }\end{array}$ & EMG:N NCV \\
\hline 27 & $F / 40$ & $\begin{array}{r}\mathbf{R} \text { ulnar nerve } \\
\text { entrapment }\end{array}$ & $R$ focal dystonia & $\begin{array}{l}\text { Occupational cramp } \\
\text { and } R \text { focal } \\
\text { dystonia }\end{array}$ & 4 years & None & $\begin{array}{c}\text { EMG:Abn } \\
\text { NCV:Abn }\end{array}$ \\
\hline 28 & $\mathbf{M} / 32$ & RSCM & $\begin{array}{l}\text { Torticollis to } L \text { and } \\
\text { head turn }\end{array}$ & Same & 26 years & Family history of ET & NA \\
\hline
\end{tabular}

Key: A = absent, Abn = abnormal, ARC = Aids related complex, BKA = below the knee amputation, EMG = electromyography, ET = essential tremor GSW = gun shot wound, $\mathrm{L}=$ Left, $\mathrm{N}=$ Normal, $\mathrm{NA}=$ not available or not done, $\mathrm{NCV}=$ nerve conduction velocities, $\mathrm{PEMG}=$ polyelectromyography, $\mathrm{R}=$ Right, $\mathrm{RSCM}=$ right sternocleidomastoid muscle, RSD = reflex sympathetic dystrophy, SEPs = somatosensory evoked potentials.

the skin and bone of the affected limb (patients $1,2,3$, $4,8,14,15,17$ and 18 ). A tenth patient (patient 20) with RSD had tremor of the affected right arm. EMG and NVC studies were performed in 18 patients, only four (patients 4, 14, 20 and 23) of whom showed decreased NCVs in at least one peripheral nerve and denervation changes of some muscles of the affected limb. PEMG recordings in four patients with focal dystonia showed abnormal motor unit activity including overflow to contiguous muscle groups, co-activation of motor units in antagonist muscles during voluntary movements, motor unit activity in shortened muscles and spontaneous synchronous bursts of motor unit activity in antagonist muscle groups. In patient 9 with "painful leg-moving toes syndrome" a PEMG recording showed features of dystonia with bursts of motor unit activity at frequency of $2-3 \mathrm{~Hz}$ and duration of approximately 500 to $800 \mathrm{~ms}$ in flexors and extensors of toes of the left foot and in the left adductor digitorum minimi (fig 1). The amplitude and frequency of the bursts increased during vibratory tonic stimulation to tendons of the left quadriceps muscle (fig 2). During a 20 minute ischaemic test induced by a pressure cuff proximal to the affected muscles the rhythmic motor unit activity ceased, while volitional movement of these muscles was still present (fig 3).

Fifteen of 23 patients $(65 \%)$ had possible predisposing factors for developing a movement disorder. These included previous use of central neuroleptics or stimulants (patients 1, 3, 8, 12, 20, 21 and 23), AIDS related complex (ARC) (patient 19), coexistent essential tremor (patients 10 and 17), premature birth (patient 4), developmental delay (patient 6), and a family history of essential tremor or dystonia (patients $5,7,13$ and 18) (table 1). The following patients were

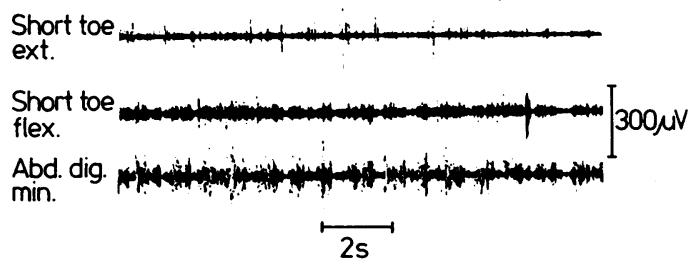

Fig 1 Patient 9: PEMG showing spontaneous asynchronous bursts of motor unit activity (frequency 2-3 Hz, duration $500-800 \mathrm{~ms}$ ) in flexors and extensors of toes of the left foot and in the left adductor digitorum mimimi.

selected to illustrate the relationship between peripheral injury and subsequent movement disorder.

\section{Patient 1}

A 33 year old woman of Ashkenazi Jewish origin injured her right elbow when she hit the wall during a racquetball game. Immediately after the injury she had pain in the right elbow which radiated into the right forearm and fourth and fifth digits of the right hand. She had a weak grip and painful swelling and discolouration of her right forearm and hand. Several sympathetic blocks transiently relieved the pain and reduced the purplish discolouration, swelling and tingling sensation. Because of pain, she wore a cast on the right forearm and elbow for a period of 10 months. Immediately after removing the cast she noticed a painless, involuntary flexion of the fourth finger gradually followed by flexion of the fifth and third digits (fig 4). She had flexion-extension tremor of the right hand. Her handwriting deteriorated and eventually became illegible. She then underwent right ulnar nerve decompressive surgery, which was repeated several months later. In both instances, scar tissue was removed around the ulnar nerve at the elbow.

Seven years previously she had been hospitalised for psychosis and bipolar depression and was treated with high 
Ext. dig. long

Short toe ext.

Tri. sur.

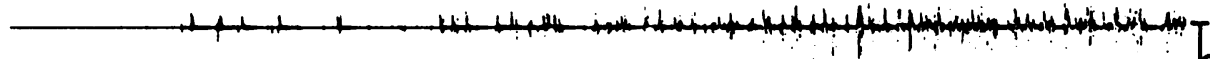

Long toe

flex.

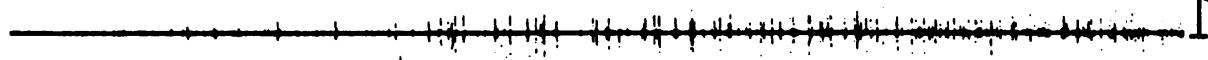

Short toe flex.

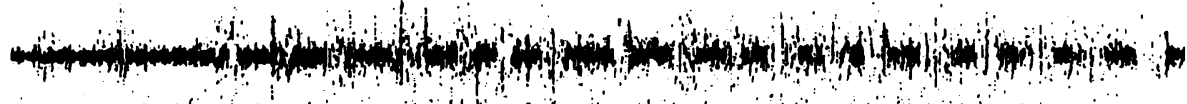

Abduct. dig. min.

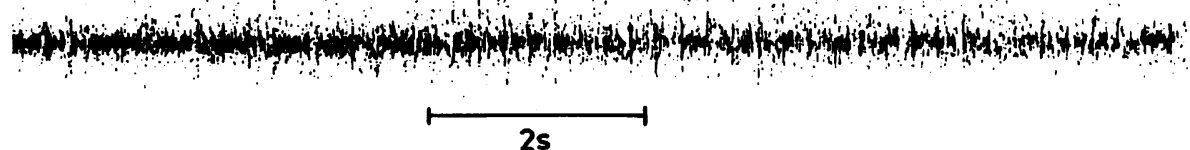

Fig 2 Patient 9: PEMG recording showing increased amplitude and frequency of bursts during vibration of the left quadriceps muscle. Note spontaneous motor unit activity in previously silent left extensor digitorum longus, flexor digitorum longus and triceps surae muscles.

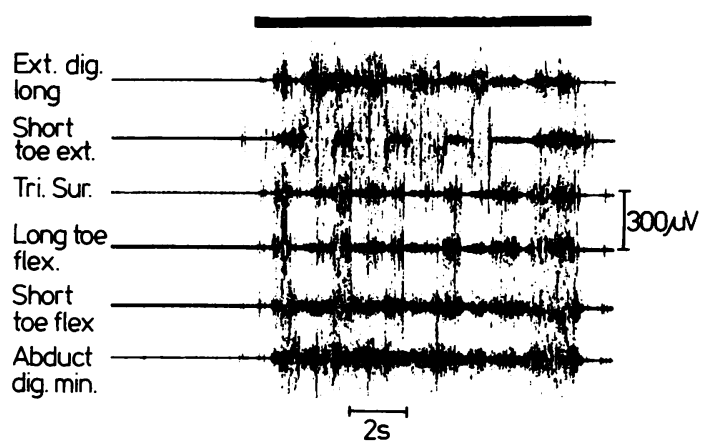

Fig 3 Patient 9: PEMG showing cessation of spontaneous bursts during ischaemia of affected leg after 20 minutes. Note preservation of volitional contractions. (bar)

doses of neuroleptics for several months. Her mother also had psychiatric problems.

MRI of the brain was normal and CSF homovanillic acid (HVA) and 3-methoxy-4-hydroxy phenylethylaminoglycol (MHPG) were abnormally decreased. Brainstem evoked potentials, and SEPs to stimulation of the tibial and median nerves were normal. PEMG recordings of muscle groups in both arms and neck showed continuous tonic motor unit discharges of the right proximal and distal arm antagonist muscles with overflow of motor unit activity to left arm and neck muscles during volitional movement. The focal right arm dystonia gradually progressed over the next 2 years to a generalised dystonia, which responded poorly to medication, including high-dose anticholinergics, tetrabenazine, and benzodiazepines. Botulinum toxin injection into the forearm finger flexors provided moderate relief of the flexion spasms,

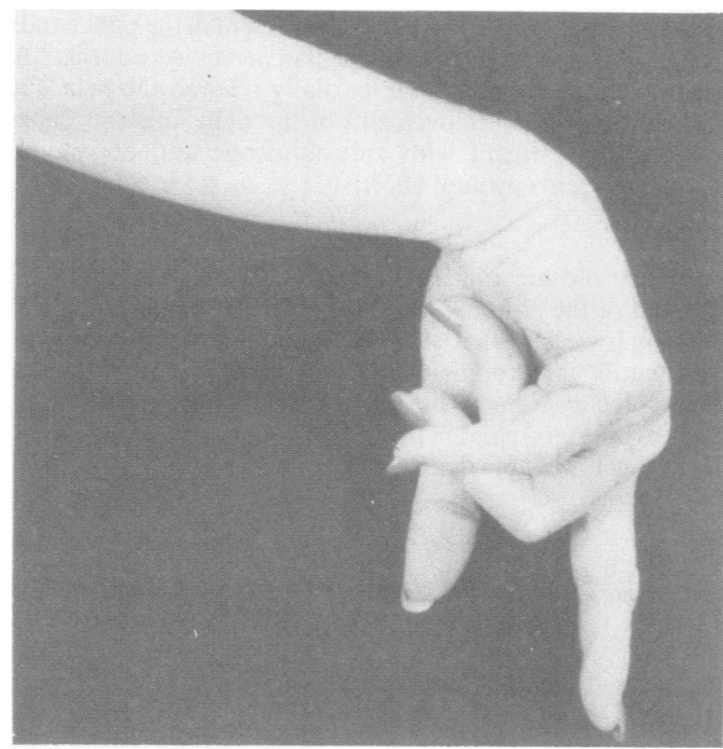

Fig 4 Patient 1: dystonic posturing of right hand.

but there was little improvement in function. Possible predisposing factors in this patient included Ashkenazi Jewish origin, and the prior use of neuroleptic drugs.

\section{Patient 2}

A 30 year old man cut his right thumb at the distal interphalangeal joint. The wound became infected and he was given antibiotics. Swelling in the right thumb persisted 


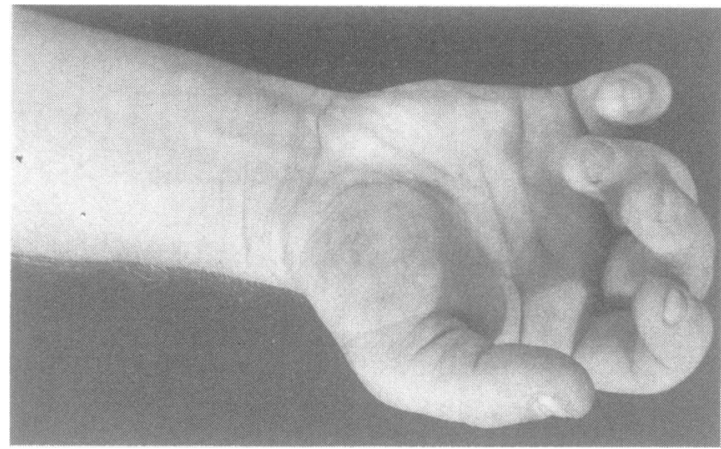

Fig 5 Patient 2: dystonic posturing of right hand.

and the hand was immobilised in a cast for 2 weeks. When the cast was removed the swelling of the right hand increased and RSD was diagnosed. At the same time he noted involuntary flexion in the fingers of the right hand and flexion at the wrist (fig 5). These cramps were extremely painful and disabling, but he was able to extend passively the fingers of the right hand. During volitional extension of the right finger, a flexion-extension tremor $(8 \mathrm{~Hz})$ was present in the right hand.

SEPs to stimulation of both median nerves were normal. A right stellate ganglion block partially relieved the pain but not the involuntary movements in the right forearm. Pharmacologic treatment with anticholinergic and dopaminedepleting agents was not effective.

\section{Patient 3}

A 33 year old supermarket cashier sustained an injury to the dorsum of the right foot when a gallon can fell on her foot. About 2 weeks later she had severe burning pain with vasomotor and trophic changes consistent with RSD. She then noted dystonic posturing of the right foot with rotation and involuntary plantar flexion (fig $6 \mathrm{a}$ and $\mathrm{b}$ ). Sensation to light touch and pin was decreased in the distal right leg.
NCVs and EMG of muscles in the affected limb were normal. PEMG showed synchronous bursts of activity with a frequency of $8 \mathrm{~Hz}$ in flexors and extensors of both wrists. Lumbar sympathectomy and a spinal epidural block only partially improved the dystonic posturing and the pain.

She had a history of depression and psychiatric hospitalisations and long-term use of neuroleptics, which once produced a temporary generalised tremor. In addition, she had complex partial seizures treated with phenytoin since puberty.

\section{Patient 4}

A 34 year old woman with a history of premature birth jumped from a truck, landing on the lateral aspect of the left foot causing acute inversion. This was immediately followed by painful swelling of the left foot and ankle. She was placed in a cast, which had to be replaced because of severe swelling. After removal of the cast 4 weeks later she noted involuntary inversion and "claw-like" deformity of the left foot and flexion of the toes. There was severe tingling and pricking pain exacerbated by slight touch, and she was unable to tolerate bed sheets on the left foot. In addition, her foot remained swollen, changed colour, the skin became dry, and the left foot was $3^{\circ}$ colder than the right (fig 7). Seven operations were performed on the foot, including arthrodesis at the ankle and of several toes. A left lumbar sympathectomy only temporarily improved the pain. Gradually, she developed sustained flexion at the left knee and hip. Touching the left foot or extending the left leg produced painful clonic flexion spasms of the entire leg at a frequency of approximately $6 \mathrm{~Hz}$. Reflexes were increased in the left leg. She had impaired perception to pinprick and temperature, light touch, vibratory sensation, and proprioception below the left knee with patchy areas of decreased sensation in areas above the knee.

SEPs to both median and tibial nerve stimulation were normal. NCVs were dimished in proximal portions, and no recording could be obtained from distal portions of the peroneal nerve of the left leg. NCVs of tibial and sural nerves were normal. In addition to continuous tonic motor unit

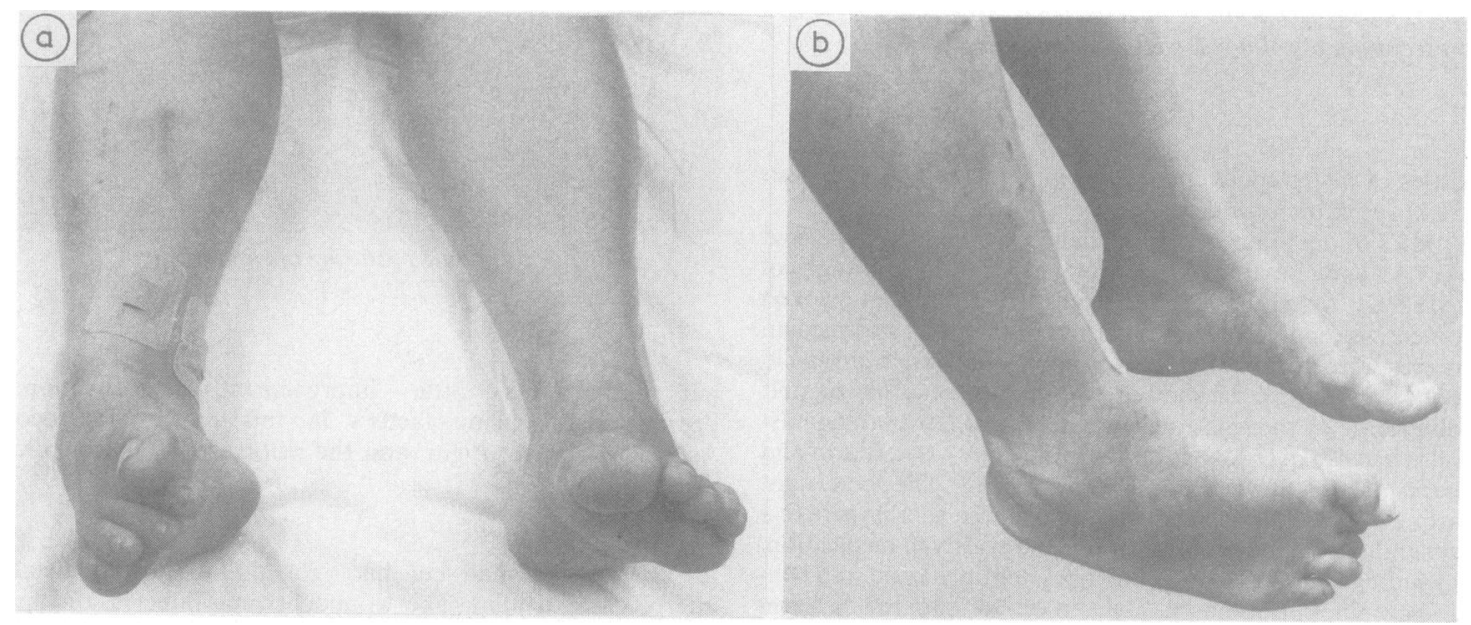

Fig 6a and b Patient 3: dystonic posturing of right foot. 


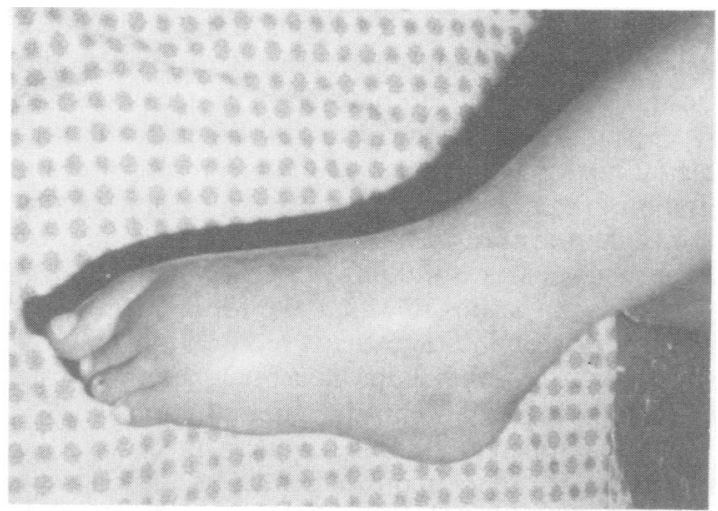

Fig 7 Patient 4: left foot deformity six years after injury.

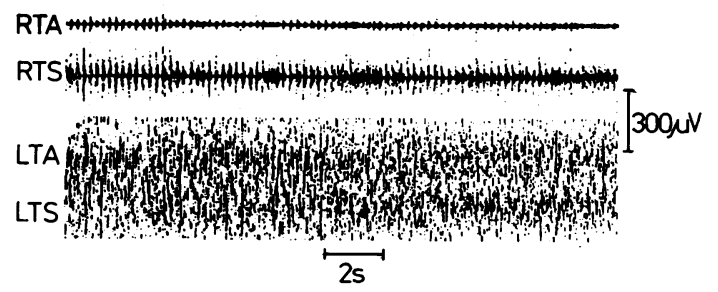

Fig 8 Patient 4: PEMG showing clonic motor unit activity (frequency $6 \mathrm{~Hz}$ ) in clinically non-affected contralateral antagonists, tibialis anterior (RTA) and triceps surae (RTS) muscles, during attempted plantar and dorsiflexion of the affected foot (LTA = left tibialis anterior, LTS = left triceps surae).

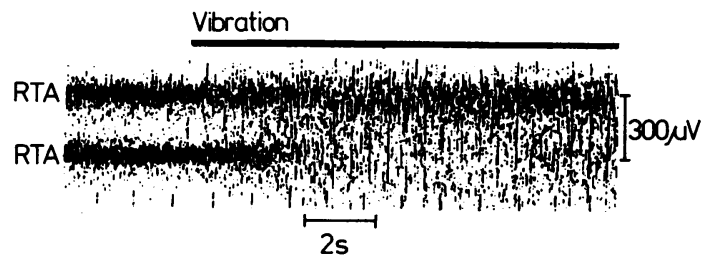

Fig 9 Patient 4: PEMG showing increased amplitude and frequency of motor unit activity in left tibialis anterior (LTA) and triceps surae (LTS) muscles during vibration of the left Achilles tendon.

activity in left foot flexors and extensors, PEMG showed clonic activity in muscle groups of the contralateral leg during attempts to move volitionally the affected leg (fig 8). Vibration to the left quadriceps greatly increased the tonic activity in the ipsilateral tibialis anterior and triceps surae muscles (fig 9). Because of persistent intractable left leg pain, a below-the-knee amputation was performed almost 7 years after the injury. Within 3 weeks after amputation she had perception of involuntary flexion and inversion of the phantom left foot.
Patient 5

A 48 year old woman with a 15 year history of familial nonkinesigenic paroxysmal dystonia had lumbar laminectomy for herniated disc after chronic low back pain. The paroxysmal dystonia, which preceded the laminectomy by about 10 years, was characterised by intermittent deviation of jaw and tongue to the left, left facial contraction, dystonic posturing of left arm and leg with abduction at the left shoulder and severe flexion at the elbow and wrist, and inversion of the left foot. The attacks occurred unpredictably, lasted several minutes, were not associated with alteration of consciousness, and were well controlled with phenytoin. Her mother, sister, brother, and son had similar paroxysmal involuntary movements of various body parts.

Within 2 months after laminectomy she noted persistent painful involuntary inversion of the left foot both at rest and during movement. She could not walk without ankle brace, and ankle orthodesis was recommended. NCV studies and EMG of the affected side were normal.

\section{Discussion}

The involuntary movements in our 23 patients consisted of focal dystonia, tremor, or both, and occurred in the distribution of previous acute injury or surgery (table 1). Among 18 patients with pre-dominant dystonia, the onset was in a hand or a forearm in seven, leg in eight, neck in two and oromandibular muscles in one. Four patients had tremor in hands and one had tremor in the legs. In this study we included only those patients with a latency between injury and the onset of movement disorder of less than 1 year; we excluded five patients with rather convincing history of posttraumatic dystonia but with a latency of more than 1 year (table 2). The purpose of our insistence on one year as the maximum latency between trauma and the movement disorder was to increase the likelihood that the involuntary movements were truly related to the peripheral injury. Marsden et al ${ }^{1}$ allowed up to 2 years and Schott $^{3}$ accepted patients up to 8 years after trauma.

The movement disorders in our patients were clinically similar to those typically seen in patients with idiopathic dystonia or essential tremor. However, our patients differed in important ways. Besides the obvious temporal relationship to prior injury, all our patients had local pain at onset of the movement disorder and 10 had RSD. Furthermore, while idiopathic focal dystonia and tremor usually occur during a task-specific activity, at least at onset ${ }^{12}$ the post-traumatic movement disorders seem to persist even at rest.

Patients with dystonia or tremor usually have no obvious cause for their involuntary movements, although in some cases specific aetiology may be identified. In our patients, no cause for their movement disorder was found except for peripheral injury, which was related in time and in distribution to 
the involuntary movement. Some patients may have had pre-existing subclinical or very mild movement disorder, which may have even contributed to the injury, and the injury merely triggered, not caused, the expression of the movement disorder. However, we were careful to exclude patients in whom the movement disorder caused entrapment or other peripheral nerve injury.

While most movement disorders are centrally generated, some are clearly due to peripheral aetiology. These include hemifacial spasm, ${ }^{6}$ segmental myoclonus, ${ }^{7}$ and involuntary movements of amputation stumps. ${ }^{9}$ It has also been suggested that spontaneous orofacial dyskinesias in some edentulous patients are a result of impaired dental proprioception. ${ }^{8}$ The "painful leg-moving toes syndrome," seen in patient 9 , may have a mixed, peripheral and central origin. ${ }^{13} 14$ Central mechanism in our patient was suggested because the abnormal EMG activity (fig 2) was abolished by peripheral ischaemia, while tonic vibration increased the frequency and amplitude of the bursts (fig 3), presumably by enhancing central afferent input. An analogous disorder is the "painful hand-moving fingers syndrome," seen in patient $12 .^{15}$ Peripheral trauma had been also implicated in other central nervous system disorders, including Parkinson's disease, ${ }^{316}$ multiple sclerosis ${ }^{17}$ and even Creutzfeldt-Jakob disease. $^{18}$

Torticollis, a common form of cervical dystonia, has been occasionally attributed to head, neck, and VIII or IX cranial nerve injury. ${ }^{10-20}$ However, in many instances the relationship between trauma and subsequent torticollis is difficult to establish and the final opinion is often influenced by psychologic and legal issues. Except for patient 19 with electric shockinduced $^{21}$ bilateral hand tremor, no other patient in our series had pending litigation. Furthermore, psychological studies in our patients showed no evidence of malingering or psychogenic aetiology of their symptoms.

How does a peripheral injury give rise to a motor disturbance that is phenomenologically similar to a centrally generated movement disorder? The frequent association between peripherally induced movement disorders and pain suggests that the motor symptoms are analogous to peripherally induced central sensory phenomenon such as the phantom pain' and certain forms of causalgia ${ }^{22-24}$ Relevant to this issue is the observation that sectioning of the peripheral roots or nerves in experimental animals can change synaptic processing at spinal segmental and suprasegmental levels..$^{25}$ Eccles et al ${ }^{26}$ and Loeser et al ${ }^{272}$ showed that deafferentiation of cat and human spinal cord causes segmental neuronal and reflex hyperexcitability in the ipsilateral cord. These and other studies 29 provide evidence that altered afferent input into spinal cord or brainstem may lead to reorganisation of the local neuronal circuitry and enhancement of evoked and spontaneous motor output, perhaps mediated via hyperexcitable gamma neurons. ${ }^{26-28}$ Whether this segmental neuronal hyperexcitability is a result of disinhibition, denervation supersensitivity, extopic excitation, ephaptic transmission, neuronal sprouting, or other mechanisms is unknown. Whatever the underlying cause, it is possible that the focal involuntary movements seen in our patients represent the clinical expression of spontaneous neuronal "burst" firing which follows partial central deafferentiation.

The peripheral trauma which preceded the movement disorders in our patients was acute, severe and well defined. However, in some patients with partially induced involuntary movements, the injury may be relatively trivial or subtle. For example, occupational cramp, a form of focal dystonia, may be associated with peripheral nerve injury related to the specific task such as excessive writing, typing, playing a musical instrument or other activities. ${ }^{12}{ }^{131}$ Newmark and Hochberg ${ }^{31}$ found dystonic finger movements in 57 instrumental musicians. While none of their subjects had pain or sensory loss, Fry, ${ }^{32}$ in another series of musicians, concluded that pain was a major symptom in those who lost function in the muscles used to play the instrument. He termed the disorder an "overuse syndrome," and attributed it to a combination of increased intensity of playing, a faulty technique, and a genetic predisposition.

Predisposition, such as specific central susceptibility to altered afferent input, may be required for the movement disorder to occur and its low frequency in the general population may explain the relative rarity of peripherally induced movement disorders when compared with the high incidence of injuries. In our study we identified possible predisposing factors in $65 \%$ of patients. Perinatal problems and the use of neuroleptic medications, both of which can lead to delayed onset dystonia ${ }^{33}{ }^{34}$ were thought to contribute to the peripherally induced movement disorders in seven patients. Two patients had essential tremor and four others had family history of essential tremor or dystonia. AIDS related complex was thought to be a predisposing factor in one patient. ${ }^{35}$ While these conditions may be merely coincidental, we propose that they may alter normal central processing and that the peripheral trauma triggers the expression of an underlying neurophysiologic abnormality. This may also explain the progression of the movement disorder to contiguous body segments and to a more diffuse motor disturbance such as generalised dystonia in patient 1 and Parkinsonism in patient $19 .^{3}$ Possible predisposing factors were also suggested in nine of 23 patients with trauma-induced dystonia reported by Brin et al, ${ }^{5}$ and in four of six patients with "painful leg- 
moving toes syndrome" described by Schoenen et al. ${ }^{13}$

Symptomatic treatment of peripherally induced dystonia and tremor with conventional medications had been disappointing. Botulinum toxin injections into the affected muscles may provide a temporary relief of spasms, but it rarely improves function. ${ }^{36}$ Sympathetic block may relieve associated pain but not the movement disorder. Further neuro-physiologic studies of sensorimotor integration should provide important insights into the pathophysiology of peripherally induced movement disorders and may aid in finding more effective therapies.

\section{References}

1 Marsden CD, Obeso JA, Traub MM, et al. Muscle spasms associated with Sudeck's atrophy after injury. $\mathrm{Br}$ Med $J$ 1984;288:173-6.

2 Schott GD. The relationship of peripheral trauma and pain to dystonia. J Neurol Neurosurg Psychiatry 1985;48:698-701.

3 Schott GD. Induction of involuntary movements by peripheral trauma: an analogy with causalgia. Lancet 1986;ii:712-6.

4 Scherokman B, Husain F, Cuetter A, et al. Peripheral dystonia. Arch Neurol 1986;43:830-2.

5 Brin MF, Fahn S, Bressman SB, Burke RE. Dystonia precipitated by trauma. Neurology 1986;36(Suppl 1):119.

6 Digre K, Corbett JJ. Hemifacial spasm: differential diagnosis, mechanism and treatment. In: Jankovic J, Tolosa E, eds. Facial Dyskinesias, Adv Neurol, Vol 49. New York: Raven Press, 1988:151-76.

7 Jankovic J, Pardo R. Segmental myoclonus: clinical and pharmacologic study. Arch Neurol 1986;43:1025-3.

8 Koller WC. Edentulous orodyskinesia. Ann Neurol 1983;13:97-9.

9 Jankovic J, Glass JP. Metoclopramide-induced phantom dyskinesia. Neurology 1985;35:432-5.

10 Sheehy MP, Marsden CD. Trauma and pain in spasmodic torticollis. Lancet 1980;i:777-8.

11 Drake ME. Spasmodic torticollis after closed-head injury. J Natl Med Assoc 1987;79:561-3.

12 Rosenbaum F, Jankovic J. Task-specific focal tremor and dystonia: categorization of occupational movement disorders. Neurology 1988;38:522-7.

13 Schoenen J, Gonce M, Delwaide PJ. Painful legs and moving toes: a syndrome with different physiopathologic mechanisms. Neurology 1984;34:1108-12.

14 Schott GD. "Painful legs and moving toes:" the role of trauma. $J$ Neurol Neurosurg Psychiatry 1981;44:344-6.

15 Verhagen VIM, Horstink MWIM, Notermans SLH. Painful arm and moving fingers. J Neurol Neurosurg Psychiatry 1985;48: 384-9.

16 Ward CD, Duvoisin RC, Ince SE, et al. Parkinson's disease in 65 pairs of twins and in a set of quadruplets. Neurology 1983;33: 815-24.

17 Miller H. Trauma and multiple sclerosis. Lancet 1964;i:848-50.

18 Kondo K, Kuroiwa Y. A case control study of Creutzfeldt-Jakob disease: association with physical injuries. Ann Neurol 1982; 11:377-81.

19 Shima F, Fukui M, Matsubara T, Kitamura K. Spasmodic torticollis caused by vascular compression of the spinal accessory root. Surg Neurol 1986;26:431-4.

20 Bronstein AM, Rudge P, Beechey AH. Spasmodic torticollis following unilateral VIII nerve lesions: neck EMG modulation in response to vestibular stimuli. J Neurol Neurosurg Psychiatry 1987;50:580-6.

21 Farrell DF, Starr A. Delayed neurologic sequelae of electric injuries. Neurology 1968;18:601-7.

22 Janig W. Causalgia and reflex sympathetic dystrophy: in which way is the sympathetic nervous system involved? Trends Neurosci 1985;8:471-7.

23 Schott GD. Mechanisms of causalgia and related clinical conditions. The role of the central and of the sympathetic nervous systems. Brain 1986;109:717-38.

24 Schwartzman RJ, McLellan TL. Reflex sympathetic dystrophy. Arch Neurol 1987;44:555-61.

25 Kaas JH, Merzenich MM, Killackey HP. The reorganization of somatosensory cortex following peripheral nerve damage in adult and developing mammals. Ann Rev Neurosci 1984;6:325-56.

26 Eccles RM, Kozak W, Westerman RA. Enhancement of spinal monosynaptic reflex responses after denervation of synergic hind-limb muscles. Exp Neurol 1962;6:451-64.

27 Loeser JD, Ward AA. Some effects of deafferentiation on neurons of the cat spinal cord. Arch Neurol 1967;17:629-36.

28 Loeser JD, Ward AA, White LE. Chronic deafferentiation of human spinal cord neurons. J Neurosurg 1968;29:48-50.

29 Bratslavsky M, vander Eecken $\mathbf{H}$. Altered synaptic organization in facial nucleus following facial nerve regeneration: an electrophysiological study in man. Ann Neurol 1977;2:71-3.

30 Hochberg FH, Leffert RD, Heller MD, Merriman L. Hand difficulties among musicians. JAMA 1983;249:1869-72.

31 Newmark J, Hochberg FH. Isolated painless manual incoordination in 57 musicians. J Neurol Neurosurg Psychiatry 1987;50: 291-5.

32 Fry HJH. Overuse syndrome in musicians: prevention and management. Lancet 1986;ii:728-31.

33 Burke RE, Fahn S, Gold AP. Delayed onset dystonia in patients with "static" encephalopathy. J Neurol Neurosurg Psychiatry 1980;43:789-97.

34 Burke RE, Fahn S, Jankovic J, et al. Tardive dystonia: late-onset and persistent dystonia caused by antipsychotic drugs. Neurology 1982;32:1335-46.

35 Nath A, Jankovic J, Pettigrew LC. Movement disorders in patients with AIDS. Neurology 1987;37:37-41.

36 Jankovic J, Orman J. Botulinum A toxin for cranial-cervical dystonia: a double-blind, placebo-controlled study. Neurology 1987;37:616-23. 